\title{
Some of the workforce face post COVID after the acute phase of the illness: The employer's supportive role
}

\author{
Katarina Babnik ${ }^{\mathrm{a}}$, Claire Staresinic ${ }^{\mathrm{b}}$ and Žan Lep ${ }^{\mathrm{a}, *}$ \\ ${ }^{a}$ Department of Psychology, University of Ljubljana, Faculty of Arts, Ljubljana, Slovenia \\ ${ }^{\mathrm{b}}$ University of North Carolina at Chapel Hill, Eshelman School of Pharmacy, Chapel Hill, NC, USA
}

Received 10 January 2022

Accepted 30 January 2022

\begin{abstract}
. condition. psychology.

Keywords: Post COVID, return to work, support, tertiary prevention

Katarina Babnik Assist. Prof. Dr. Katarina Babnik, PhD in Psychology started her career in practice. She was working in the field of HRM for ten years. After completing her $\mathrm{PhD}$, she was employed at University of Primorska, where she lectured and performed research in the field of personnel development, occupational health, organizational psychology (occupational culture, occupational identity, socialization), and older workers. Currently she is employed at University of Ljubljana, Faculty of Arts, Department of Psychology, where she lectures courses in the field of work and organizational psychology.
\end{abstract}

BACKGROUND: A considerable proportion of workers that recover from an acute phase of COVID-19 are confronted with post COVID-19 symptoms of varying severity and duration. Employers have an important role in addressing this new

OBJECTIVE: The aim of this study was to review organisational practises that could help employees suffering from long COVID-19 return to work and to link these suggestions to theoretical frameworks from the field of work and organisational

METHODS: Since scientific publications on post COVID-19 are published daily, but sound empirical studies are still scarce, the synthesis of the scientific and professional literature was performed in the form of a narrative review.

RESULTS: The results were organised according to the healthy workplace model and explained through the lens of the job demands-resources theory. The role of the employer has three aspects: collaboration, instructional pillars, and key actors. The main guidelines for implementation of the policies are an individualised approach, flexibility, and support. Supportive policies, practises, and relationships might have a direct impact on workers' psychological resources.

CONCLUSIONS: The model could help employers understand the conditions and necessary adaptations for workers with post COVID-19, as well as advance research in work and organisational psychology.

Claire Staresinic Claire Staresinic recently graduated from the University of North Carolina at Chapel Hill with a B.S. in Psychology and B.A. in German Literature and Culture. She currently

*Corresponding author: Žan Lep, University of Ljubljana, Faculty of Arts, Department of Psychology, Aškerčeva 2, 1000 Ljubljana, Slovenia. E-mail: zan.lep@ff.uni-lj.si. works as a research assistant at UNC's Eshelman School of Pharmacy. This July she will begin medical school where she hopes to conduct research on quality improvement of care in psychiatric settings.

Žan Lep Žan Lep is a Ph.D. candidate and researcher at the Department of Psychology, Faculty of Arts, University of Ljubljana. In his work, he focuses on the developmental perspectives of what motivates people, how they make decisions, and how they behave in the realms of health, civic participation, and financial functioning.

\section{Introduction}

As the COVID-19 pandemic continues, more patients are reporting prolonged symptoms after 
being infected with the SARS-CoV-2 virus. This persistence of symptoms is known as long or post COVID-19 (PC). In October 2021, the World Health Organization (WHO) [1, p. 11, 2, p. 4] published the following clinical definition of PC: "Post COVID19 condition occurs in individuals with a history of probable or confirmed SARS-CoV-2 infection, usually 3 months from the onset of COVID-19 with symptoms that last for at least 2 months and cannot be explained by an alternative diagnosis. Common symptoms include fatigue, shortness of breath, cognitive dysfunction but also others which generally have an impact on everyday functioning." Symptoms may occur in different patterns - as a continuation of the acute phase, they may recur after the acute phase, but they may also occur with a "relapsing-remitting pattern" $[1,2,3$, p.122]. Several studies suggest a significant percentage of those infected by COVID-19 experience long-term symptoms. Arnold et al. [4] demonstrated the persistence of symptoms at 8-12 weeks in $74 \%$ of patients hospitalised for COVID-19, even those admitted with mild forms of the disease. In an Italian study, only $12.6 \%$ of participants were completely free of any symptoms related to COVID-19 at the time of evaluation, two months after the onset of the first symptoms (a third had one or two symptoms while over a half of participants had three or more, even after none showed any signs or symptoms of acute illness) [5]; as of 6 June 2021, an estimated 962,000 people living in private households in the UK (1.5\% of the population) were experiencing post COVID-19 [6], while Rajan et al. [7] report an estimation that between 5 and 20\% of COVID-19 sufferers have post COVID-19 (PC).

While the knowledge about PC is still emerging, research suggests that some people, even after a mild acute phase of COVID-19 [8-10] may experience a variety of symptoms such as fatigue, shortness of breath, muscle, and joint pain, altered cognitive abilities, and sleeping problems that can last for varying lengths of time and change dynamically over time. The mechanisms and processes associated with this condition can affect one or more organs. Dennis et al. [11, p. 8] report "in low-risk individuals, there were chronic symptoms and mild impairment in the heart, lung, liver, kidney and pancreas 4 months postCOVID-19." PC is more likely to occur in some group of workers [7]. During the pandemic, health and social workers are "key workers" [12, p. 2], frontline workers who are also the most exposed to infection, but it is not yet clear whether this is associated with more severe or higher incidence of PC [3].
Studies also show that the COVID-19 outbreak and social interventions to contain the epidemic impacted the perceived stress levels and anxiety in the general population, which depend on sociodemographic and individual psychological characteristics [13-16]. A meta-analysis by Salari et al. [15] focusing on the prevalence of mental health problems in the general population during the COVID-19 pandemic showed a high proportion of the prevalence of stress, anxiety, and depression connected to the situation. Further, higher levels of perceived stress associated with the COVID-19 pandemic correlate with higher levels of depression, fear, obsessive-compulsive anxiety, neurasthenia, and hypochondria - albeit, as found by Yan et al. [16] most of the population demonstrates resilience and adaptive coping strategies.

The most reported symptoms related to PC are cognitive dysfunction, fatigue, weakness, and shortness of breath [17-19]. One study found that $85.1 \%$ of participants had experienced cognitive dysfunction, specifically poor attention or concentration, difficulty thinking, difficulty with executive functioning (planning, organising, figuring out the sequence of actions, abstracting), difficulty problem-solving or decision-making, slowed thoughts, and memory problems [17]. Other studies corroborate these findings. For example, Zhou et al. [20] found that patients who had recovered from COVID-19 still exhibited impaired sustained attention 2-3 weeks after infection. A smaller study by Miskowiak et al. [21] found that between 59 and $65 \%$ of its patients demonstrated clinically significant cognitive impairment, with verbal learning and executive functions being most affected, 3-4 months after hospital discharge. Other studies also point to long-term cognitive symptoms in patients after the acute phase of COVID-19 independent of possible covariates, such as demographic characteristics, age, mental health problems and previous anamnestic data [22, 23]. These observations reflect previous research on other coronaviruses. Follow-up studies ranging from 6 weeks to 39 months post-infection with other SARS-CoV or MERS-CoV indicated that more than $15 \%$ of patients reported ongoing emotional lability, impaired concentration, impaired memory, insomnia, and fatigue [24]. Michelen et al. [19] report weakness and malaise as the most prevalent symptoms among its sample, while fatigue was experienced by $77.7 \%$ of participants and postexertional malaise by $72.2 \%$ in a study by Davis et al. [17].

Several authors point to the similarity of the symptoms of PC to those of post-infectious 
(post-viral) fatigue syndrome (PVFS) or myalgic encephalomyelitis [25-28]. The former, however, often has different characteristics compared to PVFS [27]. PVFS is a long-term, dynamic condition [29] that follows pandemic, non-pandemic, or non-viral infectious diseases [25] with persistent or recurrent chronic fatigue and other symptoms. The Centers for Disease Control and Prevention [30] defines three primary symptoms of PVFS: (i) significantly reduced ability to perform daily activities accompanied by fatigue that persist for six months or longer, (ii) worsening of symptoms after physical or mental activity, and (iii) sleeping problems. Besides these and other possible symptoms, at least one of the following two must also be present for the PVFS diagnosis: cognitive problems (problems with memory, attention, concentration, not being able to think clearly - i.e., "brain fog") or "orthostatic intolerance" (worsening of symptoms if a person is standing or sitting upright) [30]. PVFS results in impaired functioning with biopsychosocial disabilities and impairments in performing everyday social roles [29]. A recent review [31] estimates the overall prevalence of PVFS in the general population to be $0.89 \%$, with estimated prevalence varying by participant, diagnostic criteria, and diagnostic methods. Although PC symptoms resemble those of PVFS, a narrative review [27] concluded that current knowledge does not support conclusions that COVID-19 causes PVFS as known and described in relation to previous infectious diseases and diagnostic criteria, and point out that stress, connected to the pandemic itself and viral infection, might have an additional role.

Much of the literature on PC is focused on healthcare workers or the general population. However, there is research to suggest that the working population is most affected. Some evidence shows that people younger than 70 are more commonly and severely infected by PC [32]. According to the same report, the UK's Office for National Statistics PC [6] estimated that the prevalence of symptoms was highest among 35-49-year-olds and 50-69-yearolds, compared to the general population five weeks after testing positive for COVID-19. Furthermore, in the working population, fear of job loss and future job insecurity, quarantine, unsafe work environments, infection and/or spreading the infection to those close to them for those working in "frontline" jobs, and COVID-19 related discrimination and/or stigma are all additional factors that may worsen the psychological state of the individual [33]. These adverse effects of PC on the working population can potentially create a significant societal burden.

\subsection{Working capacity and post COVID-19}

Patients experiencing PC suffer not only from the health problems associated with their condition, but also report the adverse effects on their working capacity and quality of life, which is especially troubling considering the prevalence of $\mathrm{PC}$ in the working age population. Davis et al. [17] report that only a third of respondents with persisting symptoms who worked before becoming ill were working as many hours as they were prior to becoming ill at the time of survey. Nearly half of unrecovered respondents were working reduced hours, and more than a fifth were not working at all as a direct result of their illness at the time of the survey. Moreover, many respondents who did return to work experienced relapses triggered by the mental exertion and stress related to work, often needing to go back on leave [17].

Regarding the quality of life of individuals affected by PC, almost half of patients experienced a worsened quality of life [5]. In another large survey, 634,000 people $(65.9 \%$ of those with self-reported PC) reported that their symptoms adversely affected their day-to-day activities and 178,000 (18.5\%) reported that their ability to undertake their day-to-day activities had been "limited a lot" [6] . Before becoming symptomatic, roughly two thirds of respondents said they were very/moderately physically active, and, at the time of the survey, a similar percentage of participants reported being sedentary or mostly sedentary [34]. Over time, the symptoms and related functional ability, work productivity, and quality of life of people with PC improve, yet a large proportion of symptoms and associated reduced ability persist after six months from the initial illness, such as fatigue, dyspnoea, muscle and joint pain, headache, dizziness, heart palpitation and others [35].

\subsection{Chronic diseases and return to work}

Chronic diseases and conditions are not only a problem for the health, social and labour law systems, but also for the economy. In a systematic review of the literature and a meta-analysis of previous research, Sanchez-Ramirez et al. [36] find that although an average of 8 out of 10 patients with COVID-19 return to work without a change in their working capacity, the relationship between PC and the working capacity 6 months from the onset of the first COVID-19 
symptoms is still not clear. Rayner and Campbell [3] point out that a very small proportion of workers with PC will likely qualify for ill-health retirement, although such a solution, given the proportion of the population with PC and the currently untapped rehabilitation possibilities, is not the most viable in an economic sense. The participation of employers in the return to work of staff with PC is therefore also the social responsibility of organisations and companies, and not only the health and social systems. Experience from previous viral outbreaks [37] shows that the biggest changes following acute-phase recovery are those affecting the capacity of workers, and that these changes may persist for years after infection, manifesting as partial or complete incapacity for work such as reduced working hours or reduced physical capability. Few PVFS patients who have been on sick leave for two to three years and have other negative prognostic factors (related to their work, individual characteristics, or health status) return to work. Moreover, those who return to work have parttime and less demanding jobs [38]. Although some of the more common therapeutic approaches $[39,40]$ do not restore the ability to work to patients with PVFS, other approaches, such as a period of enforced rest, as well as flexible management of job demands and workloads adjusted to the capacity of workers, are likely to contribute to a better prognosis [38]. Similar to what Rayner and Campbell [3] point out in the case of the potential disability retirements of people with long-term and severe PC symptoms, research on the economic impacts of PVFS on individuals and the society as a whole $[41,42]$ shows that evidence-based therapies that allow people with PVFS to return to work are a more appropriate approach than disability retirement, when an individual's medical condition allows it. Reynolds et al. [41] find that about a quarter of people with PVFS who would otherwise be actively involved in work are no longer working, while those who continue to work see their average monthly income reduced by a third, which represents a significant financial loss on both individual and social levels and is comparable to the loss associated with other diseases.

\subsection{Aims and methodology of literature review}

While guidelines for establishing support and assistance systems for people with PC in different areas, levels of society, and health and social systems are developing [7], more time and research will be needed to set up a comprehensive system. Therefore, there are many who point out that in the intervening period, employers have an important role to play as they can directly identify and support individuals coping with the long-term effects of COVID-19 who are returning to work [43-45]. The review of scientific and professional literature provides an overview of such calls and proposals for action.

The goal of our study was thus to review the organisational practices that could assist employees suffering from PC in their return to work. In addition, we connected the existing proposals of organisational practices aimed at supporting employees with PC with theoretical frameworks from the field of work and organisational psychology.

The term return to work has several meanings. It can denote a state - either the final state, the goal, or the result of the treatment or rehabilitation - but also the process itself, which requires involvement of various experts in occupational rehabilitation [46]. This review will focus specifically on the role of the employer in the return to work of persons with PC - in the situation wherein a person's sick leave has ended, and they have been assessed as able to return to work. Since PC is a new condition with various symptoms, however, those returning to work may not be able to perform the same work assignments as before the infection, and a return-to-work process or rehabilitation is necessary.

In the time of writing this paper, scholarly publications on COVID-19 and PC are being published daily, but sound empirical studies are still sparse. Therefore, we synthesised the scientific and professional literature (recommendations for practice) in the form of a narrative review. We have included works published in the period from July to October 2021. The scientific literature has been searched in APA PsycInfo ${ }^{\circledR}$ database, APA PsycArticles ${ }^{\circledR}$, Academic Search Complete, SocINDEX with Full Text, Business Source Premier, and MEDLINE. Professional standards and guidelines were searched using Google. The literature review also includes scientific and professional literature on working capacity and PVFS [47], although a great deal of caution is required when drawing conclusions in this regard, as the characteristics of PC and PVFS are often different [3] - or as noted by Parkin et al., [47, p.7]: "traditional models of 'fit to work' do not meet the health needs of this new cohort of returning workers" after COVID-19.

As a leading framework for systematising the collected data, we used the Healthy Workplace Model of the WHO [48]. The explanations of organisational 


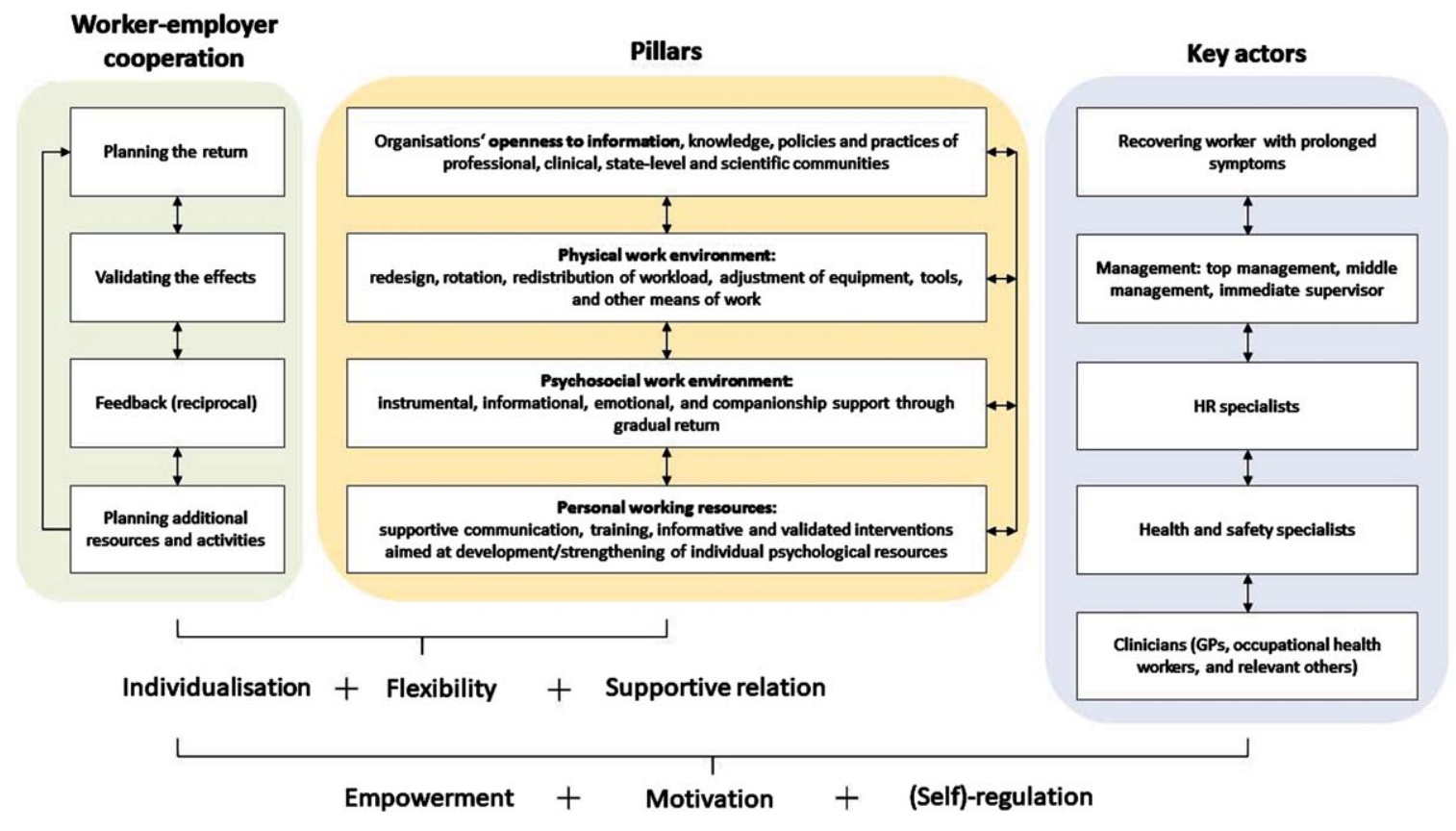

Fig. 1. Employers' roles in supporting employees returning to work with PC.

measures, good practices and policies, their effects, and underlying mechanisms, were formed based on the Job Demands-Resources Theory (JD-R) [49, 50] and other relevant psychological concepts and theories.

\section{Results}

In the first section of the literature review, we summarize the Healthy Workplace Model (HWM) [48] and present the key premises of JD-R theory [49, 50]. The next four sections present a set of measures and their basis according to the four pillars of the HWM [48]. The literature review is followed by a discussion and conclusion sections, where the discussed measures are summarised and organised into a worker support model (Fig. 1). We conclude with the limitations of the reviewed literature and provide guidelines for further psychological research on PC and returning to work.

\subsection{WHO healthy workplace model as a framework for employer's action and job demands-resources theory as an explanatory mechanism}

HWM [48] describes the operational areas, process, key stakeholders, and approaches to providing safe and healthy workplaces on a permanent basis. It identifies four key areas of planning and implementing activities for healthy workplaces and work environments: (i) physical work environment, (ii) personal health resources, (iii) enterprise community involvement, and (iv) psychosocial work involvement. Table 1 summarises the areas in the provision of healthy workplaces according to the WHO model [48].

According to the HWM, the key actors in the process of creating healthy workplaces are the management of an organisation and the actively involved workers, who account for and propose the implementation of the process of establishing, developing and maintaining health and safety in an organisation [48]. The four pillars of the WHO model [48] are linked to the JD-R theory, which describes the dynamics of the interrelationships among the pillars of a healthy workplace and explains the processes concerning the individual pillars or work environment factors that affect the health of employees and their work engagement. According to JD-R [49], a workplace can be shaped and modified by considering two elements: (i) job demands and (ii) resources. Job demands are the physical, psychological, social, and organisational characteristics of the job that require a substantial effort and can thus negatively affect the well-being of workers. Job resources are not necessarily directly 
Table 1

Key pillars of the HWM

\begin{tabular}{|c|c|}
\hline Pillar [48, p. 3] & Description \\
\hline $\begin{array}{l}\text { Physical work } \\
\text { environment }\end{array}$ & $\begin{array}{l}\text { Factors of an outdoor or indoor work environment that can be directly perceived or measured: machinery, } \\
\text { furniture, structure/architecture, products, substances, materials and processes that may affect physical or } \\
\text { mental safety and health. }\end{array}$ \\
\hline $\begin{array}{l}\text { Psychosocial work } \\
\text { environment }\end{array}$ & $\begin{array}{l}\text { Work-related stressors associated with the organisational and social aspects of work - relationships, } \\
\text { climate, culture, leadership. These factors can be characterised as prevailing beliefs, attitudes and values, as } \\
\text { well as formal or informal organisational practices that can affect the well-being and health of workers. }\end{array}$ \\
\hline $\begin{array}{l}\text { Personal health } \\
\text { resources }\end{array}$ & $\begin{array}{l}\text { Emotional, informational, and material support available to workers in a work environment - support } \\
\text { environment, health services, information, resources, opportunities, and the degree of flexibility in an } \\
\text { organisation that supports workers in their efforts to maintain and strengthen their physical and mental } \\
\text { health. }\end{array}$ \\
\hline $\begin{array}{l}\text { Enterprise } \\
\text { community } \\
\text { involvement }\end{array}$ & $\begin{array}{l}\text { Interconnectedness and interdependence of an organisation with the environment of its operation. The } \\
\text { activities, expertise and resources that the organisation exchanges with the local as well as wider } \\
\text { environment. }\end{array}$ \\
\hline
\end{tabular}

related to job demands, but refer to the physical, psychological, social, and organisational aspects of the job that facilitate workers' performance, reduce workloads or job demands, and promote individual development [49]. The two factors - demands and resources - affect workers in different ways, and these impacts may also be interconnected or interact: resources lead to positive outcomes (intrinsic motivation, commitment, improved work performance), while demands result in negative health and work-related outcomes [51]. The model further includes personal psychological resources, which represent positive self-assessments, and are positively affected by job resources, such as social support [52]. Personal psychological resources moderate (strengthen or reduce) both the negative impact of job demands on health outcomes and the positive impact of job resources on intrinsic motivation [50].

One of the key social measures in responding to a pandemic of a new disease is ensuring that the population is adequately informed, thus preventing the spread of false information, an increase in stress levels, and the disregard of the guidelines for effective measures [53-55]. With the ongoing pandemic, however, it seems that proper actions and information needed goes beyond the spread of the disease itself and includes the prolonged coping with the aftermath of the infection. In that sense, PC is a new situation for both employees and employers and is thus difficult to understand [54]. Therefore, to ensure appropriate action on the part of organisations and employees, reciprocal communication between the organisation and the local and wider environment, especially the expert community, is necessary.

\subsection{Enterprise community involvement for the exchange of credible information and reciprocal cooperation with professional practice and the scientific community}

Given the scale of the pandemic, many employers are currently already facing prolonged employee absences due to PC [56], but also PC-related presenteeism [57, 58], defined as "situations where people continue to work while unwell and not functioning to their full capacity" [59, p. 70]. Gaber et al. [60], for example, found that among health professionals who experienced PC symptoms (fatigue, shortness of breath, anxiety, sleep problems), only $16 \%$ consulted a general practitioner and only $2 \%$ opted for sick leave. There are numerous personal and work environment factors that promote presenteeism [59], such as: (i) health factors; (ii) personal factors (age, as well as gender in some studies); (iii) job type and position in the organisation, and form of employment (managerial positions, highly qualified jobs, self-employed); (iv) socioeconomic factors (employment precarity, limited access to paid sick leave); (v) people management practices and organisation of work; (vi) organisational climate; and (vii) workers' attitudes towards work - the sense of belonging, commitment, and satisfaction may motivate presence at work despite illness. In general, the diseases and conditions that are the most common causes of 
sick leave absences (i.e., musculoskeletal disorders, gastrointestinal symptoms, and mental health problems) are also the health factors most often associated with health-related presenteeism; systems that link rewards, penalties, or other "incentives" to workplace presence, regardless of the reason for the absence also promote presenteeism [59]. Furthermore, presenteeism can be exacerbated by suboptimal work schedules (long and extended working hours and shift work), demanding and stressful work tasks, time pressure, and low control over work (lack of autonomy), whereas a positive, supportive environment and relationships may both prevent and encourage presenteeism.

A cross-sectional study of almost 3,000 workers [61] shows that in addition to many of the factors listed, workers' health literacy also significantly reduces the risk of health-related presenteeism. This is also important in dealing with PC, as it is a condition caused by a novel disease that has not yet been fully studied. A qualitative study on a sample of physicians [62] showed that even medical professionals dealing with $\mathrm{PC}$ face difficulties in understanding the unusual, hitherto unknown, and persistent symptoms, as well as the feeling of not being believed by their (own) professional community. As a result, they find it necessary to emphasise the seriousness of their condition to receive appropriate additional treatment.

As coping with a new, unknown disease or condition can involve stress, anxiety, and sadness [63], the return to work of people with PC should be planned in an appropriate and expert manner, especially because the often dynamic, nonlinear disease trajectories, potentially also triggered by various job demands and workloads [3], pose an additional challenge and increase the risk of health-related presenteeism [58].

Work environments are also one of the key communities in which individuals can help mitigate other unwanted aspects of coping with a new disease or with PC [64]. Patients with COVID-19, minorities, and marginalised groups [64-67], and workers in jobs that are more exposed to infection experience stigmatisation and discrimination in association with COVID-19 and PC [68-70]. Looking into PVFS, Kingdon et al. [42] summarise that employers are less willing to accommodate workers whose illness or disability is not readily identifiable or visible. Likewise, employers' attitude towards people with PVFS is not necessarily positive or may be based on prejudices and stereotypes, which also calls for attention when dealing with employees experiencing PC.
Work environments play a significant role in reducing stigma and discrimination, especially when measures are taken to ensure a (bio-psychosocially) healthy work environment, provide psychological and financial assistance or support in obtaining it, and implement internal organisational policies aimed at reducing stigma and discrimination [64]. The first step that employers can take to contribute to a healthy work environment and support workers with PC is to provide adequate information about COVID-19 and PC. On the one hand, this will aid in reducing stigma and discrimination, but awareness and knowledge about the new disease and PC could also promote adherence to public health measures. Because an important element of the relationship between knowledge and behaviour is the perception of the credibility of information, sources on COVID-19 [55], information, education, and counselling for employees should be provided by experts in specific fields. On the other hand, employers can also contribute to knowledge about PC by being open to initiatives from the scientific community, since much research will be needed, especially into the return to work of persons with PC [3]. Cooperation with the local environment and the professional community in ensuring the safety and health of employees is therefore the necessary first step an organisation should take to provide a safe and healthy environment for returning workers who have recovered from COVID-19 and have persistent $\mathrm{PC}$ symptoms.

\subsection{Physical work environment: Re-evaluation and individualised adjustment}

The role of the physical aspects of the work environment has long been the subject of study by various disciplines. Prospective [71] and retrospective [72] studies confirm the negative impact of the adverse physical characteristics of a workplace on employee health. For example, physical stress resulting from poor working postures, lifting, carrying, pulling, and pushing loads increases the risk of long-term absence from work due to illness and the risk of early retirement $[71,73]$. The role of the physical environment in workers' health, however, can be either direct or indirect - direct in terms of stress and physiological stress response [71], and indirect when considering psychological variables such as negative affect, perception of workloads, lack of control over work, reduced motivation and productivity, as well as the interrelationships between the two kinds of effects [74]. 
In connection with the COVID-19 pandemic, the physical aspects of the work environment include work-related factors that increase the risk of infection. Such factors were (or still are) present in jobs where workers had to continue working under risk of infection despite the outbreak (e.g., healthcare, social services, and other areas of work involving direct contact with people) [75]. Nguyen et al. [76] note a significant increase in the risk of COVID-19 infection among healthcare professionals compared to the general population, with this risk being highest among employees who were in direct contact with COVID-19 patients and reported lacking adequate personal protective equipment (PPE) in the workplace (or reported having to re-use it). Even with adequate PPE, though, an increased risk of infection was still present [76], highlighting the importance of other infection control measures.

Previous research on PVFS and working capacity shows that work-related limitations relate to, among others [77, p. 263]: "difficulties getting to work, communicating, learning and remembering new material, keeping appointments and meeting deadlines, making more work-related errors, increased absenteeism and lost hours, and difficulty having the energy to sustain task-related effort and concentration." Workers in workplaces with high levels of physical stress [72, 73], especially those with less control over their work [78], are at high health risk. In turn, a re-evaluation of workplace risks is required before such workers return to work, with the re-evaluation focusing on the current working capacity of the person returning to work [3]. The return to work of persons with PC specifically should also be planned according to a return-to-work procedure, which includes:

(i) an interview with the manager prior to returning to work, during which the employer's representative and the employee agree on the return-to-work process and the necessary actions aimed at evaluating job demands and the current working capacity, as well as defining the form of support and assistance provided to the employee regarding their current state $[44,45]$;

(ii) medical examination or additional investigations, especially if the work is physically strenuous [79], as PC may be associated with, for example, organ dysfunction [11]. This is especially important for workers who already had health problems or conditions prior to the infection $[44,45]$; (iii) adjustment of work assignments and workloads in cooperation with the manager and experts, adaptation of the physical work environment through adjustments in the work equipment and workspace, and various other adjustments that reduce the workload of the worker $[44,45]$.

Rayner and Campbell [3] point out that many individuals with PC may currently not be properly clinically evaluated and treated. Therefore, occupational medicine specialists should refer them to other appropriate specialists or an evaluation centre if one has been established. Furthermore, the organisations should note that due to the dynamics of PC, symptoms may also appear later - after the worker has recovered from acute COVID-19 and returned to work. In both cases (a return to work and/or that of a subsequently identified need for rehabilitation or an extended return to work process), it makes sense to use the concept of "margin of manoeuvre" [80], which Durand et al. [81, p. 197] define as "the possibility or freedom a worker has to develop different ways of working to meet production targets, without having adverse effects on his or her health." This concept considers the interactions among the individual worker, job demands, work methods and means, and the social work environment, all of which are involved in the process of workers adapting to reduced working capacity.

In cooperation with an occupational medicine specialist and other experts, the employer can contribute to the adjustment of work assignments in physically strenuous jobs, for example by introducing temporary job rotation or changes in work assignments, reassigning work tasks among the team and shortening working hours, as well as implementing modifications to directly reduce risks due to the physical factors of the work environment (e.g., introducing protective equipment, changes in the work space, modifications of work machinery and other equipment) [48]. Some of those measures (e.g., additional protective equipment, agreement among the employees to temporarily distribute the more demanding tasks among the team) can be implemented without special formal legal procedures, while others are related to labour law or disability procedures, depending on local legislation. Because the implementation of such modifications can be lengthy, the employer can also provide certain temporary exemptions (with the worker's cooperation and consent), based on consultation with an occupational medicine specialist and in cooperation with of the entire team 
(understanding, support, assistance), thus reducing the workload and risks for the worker with PC. However, in implementation of any modifications, it is also necessary to control for the workloads of other employees so that they will not be overburdened as a result [82].

Current literature on the return to work of persons with PC is limited. Nevertheless, the existing literature $[44,45,82]$ confirms that an individualised approach and flexible work planning and execution are key to effective measures ensuring a safe and healthy return to work in different environments [44, $45,83]$. In other words, as stated by The Society of Occupational Medicine [44, p.3]: "Returning to work is part of the recovery even if it must be flexible or on a phased return at first," with flexibility being also one of the key elements in the next pillar of the HWM measures [48].

\subsection{Psychosocial work environment: Giving support through decisions, policies, practices and relations}

Physical job demands are not the only source of strain on workers. Job demands can also be psychological, social, and organisational [50]. Schreuder et al. [84] report that white- and blue-collar workers differ in the type of job demands they report - bluecollar workers report higher physical job demands, while white-collar workers report higher psychological job demands. Nevertheless, physical problems such as lower back pain, respiratory problems, and fatigue are present in both groups of workers. In a study based on a sample of nurses, Roelen et al. [85] found that psychological job demands (work intensity, time pressure, work effort, conflict of roles or demands) affect sickness absences, and that this relationship is partially moderated by mental and physical health. Both studies demonstrate that different types of demands affect both physical and mental health of employees.

Within the HWM [48], the psychosocial work environment includes a variety of work-related stressors, formal and informal organisational practices, relationships, climate, and culture. People management practices and the psychosocial climate in an organisation are also among the factors of the work environment that increase the risk of presenteeism [59]. According to the JD-R model, these factors can act as job demands or job resources related to both organisational and social aspects of work [49].
Based on a review of psychosocial measures to improve the well-being of workers with PVFS [86] and proposals to improve the working conditions of workers with PC $[44,45]$, the psychosocial factors of the work environment are also an area where the employer can make a significant contribution to the well-being of people with PC. These measures directly contribute to an individualised return to work, and according to the HWM [48] fall into the category of organisation of work and work time as psychosocial elements of work:

(i) "Gradual return to work" [44, p. 6], as PC is often manifested as an exacerbation of symptoms following exertion [17]. This entails flexible agreement on the number of working hours [44] that a worker can carry out without further straining their psychophysical capacity, expressed as a percentage of working hours that they are supposed to carry out. The formal legal system for gradual adjustments to working hours differs from country to country, and this process can involve a general practitioner, occupational medicine specialist, employer, and the employee who reports on their working capacity and symptoms. The employer's role is to participate in this process and be flexible in adapting to the capacity of the worker. Employer flexibility and adaptability is also a key element in the measures presented below.

(ii) Adjustments of to the work schedule [44, 82]: the beginning and end of work and breaks during work, which are individually adapted to the worker's current working capacity. The currently known symptoms of PC $[11,17]$ also suggest that night shifts should be temporarily stopped for workers with PC.

(iii) Workload reduction [44, 82] in terms of quantity and required intensity (the time an employee is supposed to spend on a particular task), while setting clear work objectives and systems of positive feedback.

(iv) Hybrid work or a combination of teleworking and on-site work [44, 45], as PVFS research also shows that the work commute can be stressful for persons with chronic fatigue syndrome [77], although the use of screens may be more stressful for some workers with specific PC symptoms [3].

All measures presented are in line with the recommendations made by Löfgren et al. [87] for 
employers and workers with PVFS, as well as for students with PVFS [83]. Adapting to the worker's current working capacity and providing the possibility of flexible adjustments to working hours, the work schedule, rest periods, and work tasks require psychosocial support in a work environment from the employer $[49,50,52]-$ one of the main psychosocial resources defined by JD-R theory. -In work and organisational psychology, the concept of support has long played an important role and is one of the key elements in ensuring the well-being and performance of workers, as seen in the theoretical context of social exchanges - perceived organisational support [88-90], organisational climate - the support dimension of organisational climate [91], leadership - supportive leadership [92], and the support of others in the work environment - i.e. one's co-workers [93].

During the COVID-19 pandemic, support in the work environment was confirmed as one of the key elements in reducing work-related anxiety in jobs with an increased risk of infection and higher patient care workloads, such as nursing [94]. Lee [95] used a qualitative approach to study the role of emotions, psychological security, and organisational support in the transition from office to work from home during the COVID-19 pandemic. She notes that the perceived support from the employer significantly determined the psychological reactions of employees during the COVID-19 crisis. In contrast to practices of employee supervision, organisational practices such as flexibility and employee safety and health activities provide psychological security [95], which reduces stress, anxiety, and perceptions of vulnerability among employees.

The COVID-19 pandemic has also had a broader social impact, which has put further strain on some groups of employees. Meyer et al. [96] found that the pandemic, the accompanying measures or demands placed on the working population, and the resources available to people during the nationwide lockdowns (social support, autonomy at work), interacted as determinants of emotional exhaustion. As the impact of the pandemic on emotional exhaustion was only found for women, and they conclude that the pandemic has affected women significantly more than men, mainly due to the additional demands resulting from public health measures and the strengthening of the traditional social roles of women. Regardless of gender, however, the pandemic has increased the need for support mechanisms for the working population [96].
Social support - either as enacted social support or as perceived availability of social support - plays an important role in various positive individual and group activities that are important in this context: maintaining health and coping with chronic illness, coping with work-related stress, maintaining trust in institutions and the community [97-99]. An important element of the return to work of persons with $\mathrm{PC}$ is therefore the perception that the organisation is supportive, in addition to the actual or enacted support. The latter goes beyond "what people say and do to help one another cope with stress" [98, p. 31], and represents a "meaningful social action, situated within particular contexts, and undertaken for purposes by which its success may be evaluated" [98, p. 50]. The employees (partially) generalise the perceptions of enacted support, in the form of flexibility and adaptability of working conditions and the demands made by managers and other employer agents, to the entire organisation [90]. If they perceive the organisation as caring, they provide their effort, sincere communication, and loyalty in return for recognition, sense of belonging, and emotional support [88]. The belief that others (the organisation and its agents) will provide the necessary resources or support when one needs them can help buffering the stress to the same extent as enacted social support [99]. Perceived organisational support is thus important even if the PC symptoms appear later - when the person has already returned to work after initial recovery from COVID-19.

People who believe they will be treated favourably in the event of another leave of absence, additional health treatment, or the need for adjusted job demands, will likely report on their problems or distress and act accordingly (e.g., seek appropriate professional assistance), which could result in their better mental and physical health, but also longterm productivity. The perception of the organisation as supportive further reduces health-related presenteeism [59], and social support influences one's perception of a situation and one's own ability to cope with it, while also promoting the ability to cope with a stressful situation. This can reduce the likelihood or intensity of maladaptive coping with stress [97] and moderate the stress response directly and indirectly through coping strategies [100].

In summary, social support has several functions that are important for workers returning to the work environment after illness and with reduced working capacity. These functions [101] are presented in Table 2 and supplemented with examples of indi- 
Table 2

Functions of employer's enacted social support towards employees with PC and examples of practices

\begin{tabular}{|c|c|}
\hline $\begin{array}{l}\text { Functions of } \\
\text { social support } \\
{[100, \text { p. } 89]}\end{array}$ & Examples of practice \\
\hline $\begin{array}{l}\text { Instrumental } \\
\text { support }\end{array}$ & $\begin{array}{l}\text { Flexible organisation of work and working hours (work duration, schedules, break duration and intervals) in } \\
\text { accordance with the capacity of the worker and the recommendations of a general practitioner and an } \\
\text { occupational medicine specialist }[44,45,82,87] \text {. } \\
\text { Guidance and assistance in arranging legal, health-related, and, if necessary, financial matters in connection } \\
\text { with exercising the rights deriving from health and social insurances and labour law. Direct mutual assistance } \\
\text { of co-workers through the reassignment of work duties, or strengthening the work group/team, so that a worker } \\
\text { with reduced working capacity can still carry out their work. }\end{array}$ \\
\hline $\begin{array}{l}\text { Informational } \\
\text { support }\end{array}$ & $\begin{array}{l}\text { Education or individual provision of information and counselling to employees on PC by qualified experts. } \\
\text { Provision of information on returning to work and the possible adjustments to make workers feels safe and } \\
\text { accepted, as providing accurate, understandable, and up-to-date information [53] is especially important in a } \\
\text { crisis involving an unknown medical condition. }\end{array}$ \\
\hline Emotional support & $\begin{array}{l}\text { Respecting the workers' privacy, including the privacy in relation to their health condition and occupational } \\
\text { adjustments such as reduced working capacity [44, 45, 82]. Creating a safe space [99] that enables and } \\
\text { encourages the expression of feelings and concerns related to PC and work. Expressing concerns, accepting, } \\
\text { allowing and encouraging the expression of insecurities, worries, and fears through communication }[45,82,99 \text {, } \\
\text { 101]. Providing a safe space for communication of symptoms that might be experienced after the recovery from } \\
\text { COVID-19 and return to work, or the change in their intensity; the workers need to feel safe about reporting to } \\
\text { their employer any changes in their situation and the impact their health condition has on their work. }\end{array}$ \\
\hline $\begin{array}{l}\text { Companionship } \\
\text { support }\end{array}$ & $\begin{array}{l}\text { There will likely be more workers in the organisation who will face similar difficulties, PC symptoms, and the } \\
\text { process of re-adjusting to work, especially in occupations more exposed to infection. It is therefore sensible to } \\
\text { consider setting up internal support groups and activities for employees to share experiences, support, and } \\
\text { advice. This can be implemented following the examples of self-help support groups for persons with PC [7], } \\
\text { the IASC recommendations [53, p. 20], and the Society of Occupational Medicine [44, p. 6] on establishing a } \\
\text { "buddy system" within the organisation, which is intended to provide mutual support in the work environment. } \\
\text { At every step of this process, however, the workers' privacy should be respected by not disclosing their health } \\
\text { information to their colleagues. }\end{array}$ \\
\hline Validation & $\begin{array}{l}\text { Open, two-way communication that provides feedback for support and guidance [99]. Clear objectives and } \\
\text { mechanisms for verifying their achievement are an important element of support in the return to work of people } \\
\text { with PC }[44,45] \text {. Clarity of work roles, as well as role conflicts, can potentially impact health outcomes [102]. }\end{array}$ \\
\hline
\end{tabular}

vidual support functions implemented in accordance with the possible measures for adapting the work environment to the needs of workers with PC $[44,45]$ and PVFS [87], as well as approaches to professional therapeutic communication [99]. While managers, direct supervisors, HR professionals [90], and occupational safety and health professionals all play a role in social support functions, these professionals need support from top management in the form of consent and mechanisms for establishing best practices to carry out their role. Additionally, employer representatives must express sincerity in all activities, measures, and relationships they are involved in, and thus act in a "discriminating way when express- ing approving comments", and "showing consistency between words and deeds" [90, p. 178].

In a study by Lou et al. [103], healthcare workers considered the support of their family and friends as the most useful resource during the COVID-19 pandemic. At the level of the work environment, the most useful resource was the availability of adequate protective equipment and support from colleagues, while resources at the system level included job protection, information about COVID-19, and public health measures. Thus, social support is one of the main resources that can directly increase motivation and reduce the negative impact of job demands on an individual [50, 103]. Furthermore, social support 
plays an important role in strengthening the individual psychological resources of the worker [50, 52].

\subsection{Personal resources: Psychological characteristics that strengthen the effect of positive organisational practices and promote (self)regulation of work activities}

As defined by HWM [48], personal resources are individual psychological variables that employers can influence directly (e.g., healthy lifestyle programmes) and indirectly (supportive work environment) through measures, programmes, policies, and practices aimed at empowering individuals who are returning to work. Personal resources are thus a mediating variable between work environment factors and the employees' responses [104], which are reflected in the process of regulation or selfregulation of job demands and working capacities in a return-to-work situation [80]. Such regulation can also be identified in work activities, for example in seeking and developing appropriate approaches to work, or in strategies adapted to work situations and individual working capacities. The concepts of personal resources [48] and regulation of work behaviour [80] correspond to the concepts of psychological resources and job crafting in JD-R theory [50]. In this theory, personal psychological resources are perceptions, beliefs, expectations, and stress-coping strategies [104]; in other words, "beliefs people hold regarding how much control they have over their environment" [50, p. 275], such as self-efficacy, resilience, hope, and optimism [52].

According to JD-R theory, work resources and personal psychological resources increase work motivation, which is reflected in job crafting [50]. This is a relatively recent concept that describes behaviours such as [105]: (i) adding or subtracting tasks, increasing, or reducing effort, and reorganising work tasks (task crafting); (ii) establishing and maintaining productive relationships (relational crafting); and (iii) viewing work as important and meaningful (cognitive crafting). The relationship between job crafting and resources is not unidirectional: job crafting also strengthens job resources and psychological resources of the worker [49]. The reverse, negative process, according to JD-R theory, is one that leads to exhaustion, stress, and other negative work and health outcomes. High job demands, which the worker has no influence over or a lack of sufficient personal resources to moderate the impact of high job demands on health can lead to exhaustion
[49]. Chronic exhaustion or burnout then reinforces the negative relationship between job demands and exhaustion, and reduces the positive effects of job resources, personal resources, and intrinsic motivation. This results in a closed feedback loop among exhaustion, decreased efficiency, negative perceptions and emotions, and, consequently, an increased burden on the worker [106], from which they find it difficult to exit on their own.

Current research relating to the COVID-19 pandemic and negative emotional outcomes confirms the role of personal resources in coping with the crisis. In a longitudinal study, Joie-La Marle et al. [107] found that in stressful situations, general self-efficacy acts as a stable personal psychological resource that influences adaptive performance or effective selfregulation in work activities. An intervention study by Sylvia et al. [108] confirmed the positive effects of stress management and resilience interventions on a sample of front-line healthcare workers, with the positive effects of the programme being greatest for workers with fewer personal resources and high levels of anxiety and depression prior to the programme. In a study using a sample of nurses, Roberts et al. [109] found that age and years of work experience significantly predict depression and anxiety. On the other hand, resilience, a personal psychological resource for coping with stressful situations, was significantly determined only by the age of the participants, which confirms the importance of experience, knowledge, and skills in coping with new stressful situations.

Taken together, support activities in stressful situations, which also include the reduced working capacity due to PC, should thus be focused on strengthening the belief in the ability to control one's environment. In this sense, Servellen [99] highlights the importance of two forms of control - cognitive control and behavioural control, that is, control over plans, decisions, and one's own behaviour and attitudes. Enabling such control in a work environment requires appropriate supportive communication and a relative degree of autonomy of workers, which ensures the involvement of individuals in the planning of goals and the activities to achieve them [44, 45]. While psychological resources can be developed [49], this is a long-term and systematic process to which employers can contribute. Thus, they can aid in strengthening the psychological resources of workers with PC, while also aiming for primary rather than tertiary prevention in the return to work of workers with a reduced working capacity through: 
(i) Dialogue with the employer involving workers with PC in planning of all work adjustment activities, continuous positive feedback that builds and maintains selfesteem [49]. Employers must gain feedback from the worker, rather than just providing it themselves. They must verify whether the work adjustments, such as reduced working hours and reduced workload, are still suitable and whether the worker is satisfied with them [82, 110];

(ii) Relative degree of work autonomy (harmonised with job demands and the type of job to ensure health and safety at work), which allows self-regulation [80] or job crafting [49] in modified conditions for workers with a reduced working capacity;

(iii) Training $[49,80]$ or enhancing knowledge and work skills in accordance with the reduced capacity of the worker;

(iv) Provision of information and education about PC and the systemic support measures available in the workplace and the wider (healthcare, social, labour law) context. This improves health literacy, which is an important element in the prevention of presenteeism [61], while also allowing the public to be better informed and follow health protection measures [55, 99];

(v) Validated programmes for strengthening psychological resources, such as resilience [108], or other professional programmes with a similar purpose [49], which help in the successful management of job demands. However, the need for additional research into the effects of various intervention programmes should be highlighted, as some of these programmes have not been shown to be effective for people with PVFS [39, 40];

(vi) Providing workplace support in form of job resources, which strengthen individual psychological resources [49].

\section{Discussion and conclusions}

While scientific knowledge about PC is still evolving, it is evident that a significant share of workers is recovering from an acute phase of COVID-19 and facing an onset of PC symptoms of varying severity and duration, which may affect their functional abilities and working capacity [3, 7, 17, 43-45, 82].
Today, however, there is a lack of published research on the impact of PC on working capacity and on the return to work of workers affected by this condition [3]. Furthermore, many countries are yet to implement uniform approaches to treating people with PC at the healthcare system level.

Nevertheless, there are examples of good practices with positive results. Our review of literature also supports the notion that employers have an important role to play in this process, although they may feel powerless due to the lack of established and validated approaches and the lengthy formal legal procedures. To aid this process, we designed a set of possible activities and their agents, and outlined the cooperation between workers and the employer in the return-to-work process through a narrative review of the existing literature on the measures in the return to work of persons with $\mathrm{PC}[3,44,45,82]$ and PVFS [87], as well as other theoretical and empirical research into coping strategies adopted by the working population during the COVID-19 pandemic, and based on WHM [48], JD-R theory [49, 50], the concept of return to work [80, 104], and social support [90, 98]. All these components are combined into the model presented in Fig. 1. The measures and activities depend on the degree of disability of the worker, their health status, current level of personal resources, characteristics of their job and other factors, and finally their personal life conditions and level of support [96]. Nevertheless, the model can serve as a basic guide for employers, and can inform further research, as it presents the role of some of employer measures adopted so far based on predominantly psychological theories.

The presentation of the role of the employer in the return to work of a worker who is facing long-term symptoms and/or a sudden onset of new symptoms has three key aspects: cooperation, instructional pillars, and key agents. The key agents in this process and condition are: (i) the worker who has returned to work and is facing symptoms of varying severity and type after recovering from COVID-19, most commonly fatigue $[11,17,111]$; (ii) management [45, $48,82,88$ ], which enforces occupational safety and health policies and practices, implements the necessary measures to adjust job demands and resources to workers with PC, allocates financial resources, and cooperates with professional, social, and scientific communities; and (iii) other experts employed by the organisation (in the fields of human resource management and occupational safety and health) whose role in this process is to advise top management 
and direct supervisors and assist the workers in the process of adjustment by providing support in obtaining information and exercising rights [82]. In this process, the employer, and their representatives, as well as the worker, follow the recommendations of the occupational medicine specialist and the general practitioner, who may also refer the worker for additional examinations and treatment. The employer supports the worker at every step of this process by showing understanding and respect and by encouraging the worker to participate in further diagnostic and treatment procedures, if necessary [82].

Adjusting the physical aspects of job demands is one of the primary preventive measures, especially in physically strenuous jobs $[44,82]$, since strenuous exercise, mental or physical activities, and stress can all exacerbate the condition or cause a relapse of PC symptoms [17]. Psychological factors can be present in both job demands and job resources. Communication, climate, work organisation, and organisational relationships [48] are work resources, provided they are positive or supportive. Similarly, to workers with PVFS [87], ensuring the flexibility of various aspects of the work organisation, such as working hours, schedule, work duration, break duration and intervals, is particularly important for workers with PC $[44,82]$. A key element is the gradual approach to the returnto-work process and workload distribution [44, 82]. In the context of a return to work, this element (flexibility and gradual approach to work organisation) is one of the keyways in which the employer provides instrumental support to a worker with PC. Other important facets of support include informational, emotional and companionship support, and validation [101]. Emotional support is especially important in times of stress and health-related uncertainty [99]. This type of support is primarily provided through communication, which allows and encourages the expression of feelings and concerns about stressful situations, as well as work [99, 101]. Employee support is expressed both through instrumental support (e.g., reassignment of work tasks among the team to temporarily reduce the workload of workers with PC), and in terms of companionship support [101], that is, the support of co-workers who might be facing similar PC-related problems. Informal communities that connect people with similar experiences send a direct signal to workers that they are not alone, while also offering direct emotional support as a space where experiences, insecurities, fears, and positive events can be shared and accepted. Measures, policies, practices, and organisational relationships that are supportive in nature can have a direct influence on the workers' psychological resources, as they empower individuals to face new situations and health-related challenges [48]. Personal psychological resources mediate the relationship between job demands and reduced working capacities, and the workers' responses to this situation [104]. Along with the long-term support of the employer, they contribute to effective self-regulation [80], job crafting [50], and adaptive employee performance [107]. Individual psychological resources are strengthened by job resources and adjustments in job demands, but also by other direct measures aimed at promoting positive self-perceptions and the perception of control over the environment and one's role in it [99], such as encouraging the acquisition of new skills, knowledge, and competencies [49], providing information and enhancing health literacy [61] with regard to a specific health condition, as well as by programmes and interventions specifically aimed at strengthening individual psychological resources [108]. However, such intervention programmes need to be validated in different populations and for different levels of disability before they can be put into practice. The bottom left part of Fig. 1 presents the key guidelines for implementing the measures and the entire process: an individualised approach [3], flexibility [44, 87], and supportiveness [48, 50, 99] at the levels of policy practices, decisions, and everyday relations.

Whether such a model can empower individuals, increase intrinsic motivation, and improve selfregulation at work for people with $\mathrm{PC}$ remains a question for further studies. Therefore, the model needs to be treated with great reserve - as a general guide rather than a recipe for action. The present literature review is one step towards improving the environment and functional abilities of persons with PC. However, much more research is needed, both at the level of understanding the symptoms, their duration, dynamics, and occurrence mechanisms, and at the level of the impact this condition has on working capacity [3], and the potential support programmes, interventions, and actions. The review is thus primarily a theoretical framework for understanding the psychological factors and mechanisms involved in the return to work and the role of employers in this process. Scientific articles and papers on PC were published almost daily during the preparation of this review, so it was impossible to cover everything. As knowledge about COVID-19 and PC evolves, the validity and reliability of this review will decrease. Nevertheless, it will hopefully contribute 
to practice (understanding the conditions and necessary adjustments for workers with PC) and to further theoretical research in the fields of occupational and organisational psychology and occupational health psychology.

\section{Acknowledgments}

There are no conflicts of interest associated with this publication and there has been no financial support for this work that could have influenced its outcome. The study presented in the manuscript did not receive any specific grant from funding agencies in the public, commercial, or not-for-profit sectors.

\section{Author contributions}

CONCEPTION: Katarina Babnik and Claire Staresinic

METHODOLOGY: Katarina Babnik and Claire Staresinic

DATA COLLECTION: Katarina Babnik, Claire Staresinic and Žan Lep

INTERPRETATION OR ANALYSIS OF DATA: Katarina Babnik, Claire Staresinic and Žan Lep PREPARATION OF THE MANUSCRIPT: Katarina Babnik, Claire Staresinic and Žan Lep REVISION FOR IMPORTANT INTELLECTUAL CONTENT: Katarina Babnik, Claire Staresinic and Žan Lep

SUPERVISION: Katarina Babnik

\section{References}

[1] World Health Organization (WHO). A clinical case definition of post COVID-19 condition by a Delphi consensus. [Internet]. Available from: https://apps.who.int/iris/ bitstream/handle/10665/345824/WHO-2019-nCoV-PostCOVID-19-condition-Clinical-case-definition-2021.1eng.pdf [Accessed 30 October 2021]

[2] Soriano JB, Murthy S, Marshall JC, Relan P, Diaz JV, Group WC. A clinical case definition of postCOVID-19 condition by a Delphi consensus. Lancet Infect Dis. 2021;22(4):e102-e107. DOI: 10.1016/S14733099(21)00703-9

[3] Rayner C, Campbell R. Long Covid Implications for the workplace. Occup Med. 2021;71(3):121-3. DOI: 10.1093/occmed/kqab042

[4] Arnold DT, Hamilton FW, Milne A, Morley AJ, Viner J, Attwood M, et al. Patient outcomes after hospitalisation with COVID-19 and implications for follow-up: results from a prospective UK cohort. Thorax. 2021;76(4):399401. DOI: $10.1136 /$ thoraxjnl-2020-216086
[5] Carfì A, Bernabei R, Landi F, for the Gemelli Against COVID-19 Post-Acute Care Study Group. Persistent Symptoms in Patients After Acute COVID-19. JAMA. 2020;324(6):603-5.

[6] Office for National Statistics. Prevalence of ongoing symptoms following coronavirus (COVID-19) infection in the UK. [Internet]. Available from: https://www.ons.gov. uk/peoplepopulationandcommunity/healthandsocialcare/ conditionsanddiseases/bulletins/prevalenceofongoingsym ptomsfollowingcoronaviruscovid19infectionintheuk/1july 2021 [Accessed 12 August 2021].

[7] Rajan S, Khunti K, Alwan N, Steves C, Greenhalgh T, MacDermott $N, \ldots \&$ McKee M. In the wake of the pandemic. Preparing for Long COVID. Policy Brief [Internet]. 2021;39. Available from: https://www.aps.1283ro.it/wpcontent/uploads/2021/07/Policy-brief-39-1997-

12848073-eng.pdf [Accessed 12 August 2021]

[8] Goërtz YM, Van Herck M, Delbressine JM, Vaes AW, Meys R, Machado FV, Houben-Wilke S, Burtin C, Posthuma R, Franssen FM, van Loon N. Persistent symptoms 3 months after a SARS-CoV-2 infection: the postCOVID-19 syndrome? ERJ Open Research. 2020;6(4).

[9] Townsend L, Dyer AH, Jones K, Dunne J, Mooney A, Gaffney F, O'Connor L, Leavy D, O'Brien K, Dowds J, Sugrue JA. Persistent fatigue following SARS-CoV2 infection is common and independent of severity of initial infection. PLoS ONE. 2020;15(11):e0240784. https://doi.org/10.1371/journal.pone.0240784

[10] van Kessel SA, Hartman TCO, Lucassen PL, van Jaarsveld CH. (2021). Post-acute and long-COVID-19 symptoms in patients with mild diseases: a systematic review. Fam Pract. https://www.ncbi.nlm.nih.gov/pmc/articles/ PMC8414057/

[11] Dennis A, Wamil M, Alberts J On behalf of COVERSCAN study investigators, et al. Multiorgan impairment in low-risk individuals with post-COVID-19 syndrome: a prospective, community-based study. BMJ Open. 2021;11:e048391. doi: 10.1136/bmjopen-2020-048391

[12] Murphy E, McDowall K, McDowall P. Should long-term symptoms following COVID-19 infection be considered an occupational disease? Occup Med, 2021;kqab103. DOI: $10.1093 /$ occmed/kqab103

[13] Flesia L, Monaro M, Mazza C, Fietta V, Colicino E, Segatto B, Roma P. Predicting perceived stress related to the Covid-19 outbreak through stable psychological traits and machine learning models. J Clin Med. 2020;9(10):3350. DOI: 10.3390/jcm9103350

[14] Fiorenzato E, Zabberoni S, Costa A, Cona G. Cognitive and mental health changes and their vulnerability factors related to COVID-19 lockdown in Italy. PLoS ONE. 2021;27 16(1):e0246204.

[15] Salari N, Hosseinian-Far A, Jalali R, Vaisi-Raygani A, Rasoulpoor S, Mohammadi M, Rasoulpoor S, KhalediPaveh B. Prevalence of stress, anxiety, depression among the general population during the COVID-19 pandemic: a systematic review and meta-analysis. Glob Health. 2020;16(1):1-11. DOI: 10.1186/s12992-020-00589-w

[16] Yan L, Gan Y, Ding X, Wu J, Duan H. The relationship between perceived stress and emotional distress during the COVID-19 outbreak: Effects of boredom proneness and coping style. J Anxiety Disord. 2021;77:102328. DOI: 10.1016/j.janxdis.2020.102328 
[17] Davis HE, Assaf GS, McCorkell L, Wei H, Low RJ, Re'em Y, et al. Characterizing long COVID in an international cohort: 7 months of symptoms and their impact. EClinicalMedicine. 2021;101019. DOI: 10.1016/j.eclinm.2021.101019

[18] Vanichkachorn G, Newcomb R, Cowl CT, Murad MH, Breeher L, Miller S, et al. Post-COVID-19 Syndrome (Long Haul Syndrome): Description of a Multidisciplinary Clinic at Mayo Clinic and Characteristics of the Initial Patient Cohort. Mayo Clin Proc. 2021;96(7):1782-91.

[19] Michelen M, Cheng V, Manoharan L, Elkheir N, Dagens $\mathrm{D}$, Hastie $\mathrm{C}$, et al. Characterising long term Covid19: a living systematic review. BMJ Global Health. 2021;6:e005427. DOI: 10.1136/bmjgh-2021-005427

[20] Zhou H, Lu S, Chen J, Wei N, Wang D, Lyu H, et al. The landscape of cognitive function in recovered COVID19 patients. J Psychiatr Res. 2020;129:98-102. DOI: 10.1016/j.jpsychires.2020.06.022

[21] Miskowiak K, Johnsen S, Sattler S, Nielsen S, Kunalan K, Rungby J, et al. Cognitive impairments four months after COVID-19 hospital discharge: Pattern, severity and association with illness variables. Eur Neuropsychopharmacol. 2021;46:39-48. DOI: 10.1016/j.euroneuro.2021.03. 019

[22] Hampshire A, Trender W, Chamberlain SR, Jolly AE, Grant JE, Patrick F, Mazibuko N, Williams SC, Barnby JM, Hellyer P, Mehta MA. Cognitive deficits in people who have recovered from COVID-19. EClinicalMedicine. 2021;39:101044. DOI: 10.1016/j.eclinm.2021.101044

[23] Delgado-Alonso C, Valles-Salgado M, Delgado-Álvarez A, Yus M, Gómez-Ruiz N, Jorquera M, Polidura C, Gil MJ, Marcos A, Matías-Guiu J, Matias-Guiu JA. Cognitive dysfunction associated with COVID-19: a comprehensive neuropsychological study. [Preprint]. Available from: https://assets.researchsquare.com/files/rs-704742/v1/8f1 8c43e-0d51-4e5f-83e3-ed6f74d4ec7b.pdf?c=16318864 40 [Accessed 20 December 2021].

[24] Rabinovitz B, Jaywant A, Fridman CB. Neuropsychological functioning in severe acute respiratory disorders caused by the coronavirus: Implications for the current COVID19 pandemic. Clin Neuropsychol. 2020;34(7-8):1453-79. DOI: $10.1080 / 13854046.2020 .1803408$

[25] Islam MF, Cotler J, Jason LA. Post-viral fatigue and COVID-19: lessons from past epidemics. Fatigue: Biomed. Health Behav. 2020;8(2):61-9. DOI: 10.1080/ 21641846.2020.1778227ž

[26] Perrin R, Riste L, Hann M, Walther A, Mukherjee A, Heald A. Into the looking glass: Post-viral syndrome post COVID-19. Med. Hypotheses. 2020;144:110055. DOI: 10.1016/j.mehy.2020.110055

[27] Poenaru S, Abdallah SJ, Corrales-Medina V, Cowan J. COVID-19 and post-infectious myalgic encephalomyelitis/chronic fatigue syndrome: a narrative review. Ther Adv Infect Dis. 2021;8:20499361211009385. DOI: $10.1177 / 20499361211009385$

[28] Lyons D, Frampton M, Naqvi S, Donohoe D, Adams G, Glynn K. Fallout from the COVID-19 pandemic-should we prepare for a tsunami of post viral depression? Ir J Psychol Med. 2020;37(4):295-300. DOI: 10.1017/ipm. 2020.40

[29] Stormorken E, Jason LA, Kirkevold M. Factors impacting the illness trajectory of post-infectious fatigue syndrome: a qualitative study of adults' experiences. BMC public health. 2017;17(1):1-8. DOI: 10.1186/s12889-017-49 68-2

[30] Centers for Disease Control and Prevention (CDC). Symptoms of ME/CFS. [Internet]. 2021. Available from: https://www.cdc.gov/me-cfs/symptoms-diagnosis/sympt oms.html [Accessed 28 September 2021]

[31] Lim EJ, Son CG. Review of case definitions for myalgic encephalomyelitis/chronic fatigue syndrome (ME/CFS). J Transl Med. 2020;18:289. DOI: 10.1186/s12967-02002455-0

[32] What might long COVID mean for the nation's health? The Health Foundation [Internet]. Available from: https:// www.health.org.uk/news-and-comment/blogs/what-migh t-long-covid-mean-for-the-nations-health [Accessed 12 August 2021]

[33] Giorgi G, Lecca LI, Alessio F, Finstad GL, Bondanini G, Lulli LG, Arcangeli G, Mucci N. COVID-19-related mental health effects in the workplace: a narrative review. Int J Environ Res Public Health. 2020;17(21):7857. DOI: 10.3390/ijerph17217857

[34] Report: What Does COVID-19 Recovery Actually Look Like? - Patient Led Research Collaborative [Internet]. Available from: https://patientresearchcovid19. com/research/report-1/ [Accessed 12 August 2021]

[35] Vaes AW, Goërtz YM, Van Herck M, Machado FV, Meys R, Delbressine JM, Houben-Wilke S, Gaffron S, Maier D, Burtin C, Posthuma R. Recovery from COVID-19: a sprint or marathon? 6-month follow-up data from online long COVID-19 support group members. ERJ Open Res. 2021;7(2). DOI: 10.1183/23120541.00141-2021

[36] Sanchez-Ramirez DC, Normand K, Zhaoyun Y, TorresCastro R. Long-term impact of COVID-19: A systematic review of the literature and meta-analysis. Biomedicines. 2021;9(8):900. DOI: 10.3390/biomedicines 9080900

[37] Reukers DF, van Loenhout JA, Roof I, Senden TF, Keijmel SP, Bleeker-Rovers CP, van Jaarsveld CH, Hautvast JL, van der Velden K. Impact of Q-fever fatigue syndrome on patients' work status. Occupational Medicine. 2020;70(8):578-85. Occup Med. 70(8):578-585. DOI: 10.1093/occmed/kqaa166

[38] Vink M, Vink-Niese F. Work rehabilitation and medical retirement for myalgic encephalomyelitis/chronic fatigue syndrome patients. A review and appraisal of diagnostic strategies. Diagnostics. 2019;9(4):124. DOI: 10.3390/diagnostics9040124

[39] Vink M, Vink-Niese A. Could Cognitive Behavioural Therapy Be an Effective Treatment for Long COVID and Post COVID-19 Fatigue Syndrome? Lessons from the Qure Study for Q-Fever Fatigue Syndrome. Healthcare. 2020;8(4):552. DOI: 10.3390/healthcare8040552

[40] Vink M, Vink-Niese, F. Graded exercise therapy does not restore the ability to work in ME/CFS-Rethinking of a Cochrane review. Work. 2020;66(2):283-308. DOI: 10. 3233/WOR-203174

[41] Reynolds KJ, Vernon SD, Bouchery E, Reeves WC. The economic impact of chronic fatigue syndrome. Cost Eff Resour Alloc. 2004;2(1):1-9. DOI: 10.1186/1478-75472-4

[42] Kingdon CC, Bowman EW, Curran H, Nacul L, Lacerda EM. Functional Status and Well-Being in People with Myalgic Encephalomyelitis/Chronic Fatigue Syn- 
drome Compared with People with Multiple Sclerosis and Healthy Controls. PharmacoEconomics - open. 2018;2(4):381-392. DOI: 10.1007/s41669-018-0071-6

[43] Stewart-Patterson C, Bourgeois R, Martin DW. The Importance of Keeping Patients with Post-Acute Sequelae of SARS-CoV-2 Infection (Long COVID) Engaged in Work. Am Fam Physician. 2021;103(12):710. https://www.aafp.org/afp/2021/0615/p710.html

[44] The Society of Occupational Medicine. COVID-19 return to work guide: for recovering workers. 2021. [Internet]. Available at: https://www.som.org.uk/COVID19_return_to_work_guide_for_recovering_workers.pdf [Accessed 10 October 2021]

[45] The Society of Occupational Medicine. COVID-19 return to work guide: for managers. 2021. [Internet]. Available at: https://www.som.org.uk/COVID-19_return_to_work_ guide_for_managers.pdf [Accessed 10 October 2021]

[46] Schultz IZ, Stowell AW, Feuerstein M, Gatchel RJ. Models of return to work for musculoskeletal disorders. J Occup Rehabil. 2007;17(2):327-52.

[47] Parkin A, Davison J, Tarrant R, Ross D, Halpin S, Simms A, Salman R, Sivan M. A Multidisciplinary NHS COVID19 Service to Manage Post-COVID-19 Syndrome in the Community. J Prim Care. 2021;12:21501327211010994. DOI: $10.1177 / 21501327211010994$

[48] World Health Organization. WHO Healthy Workplace Framework and Model: Background and Supporting Literature and Practices. [Internet]. Available from: https:// www.who.int/occupational_health/HealthyWorkplaces_B ackgrounddoc.pdf [Accessed 10 August 2021]

[49] Bakker AB, Demerouti E. Job Demands-Resources theory. In Cooper C, Chen P (Eds.), Wellbeing: A complete reference guide. Chichester, UK: Wiley-Blackwell; 2014: pp. 37-64. DOI: 10.1002/9781118539415.wbwell019

[50] Bakker AB, Demerouti E. Job demands-resources theory: Taking stock and looking forward. J. Occup. Health Psychol. 2017;22(3):273-85. DOI: 10.1037/ocp0000056

[51] Schaufeli WB, Taris TW. A critical review of the job demands-resources model: Implications for improving work and health. In: Bauer GF, Hämmig O, (eds.). Bridging Occupational, Organizational and Public Health: A Transdisciplinary Approach. Springer Science + Business Media; 2014:43-68.

[52] Kerksieck P, Bauer GF, Brauchli R. Personal and social resources at work: Reciprocal relations between crafting for social job resources, social support at work and psychological capital. Front. Psychol. 2019;10. DOI: 10.3389/fpsyg.2019.02632

[53] Basic Psychosocial Skills: A Guide for COVID-19 Responders. IASC Inter-Agency Standing Committee [Internet]. 2020. Available from: https://interagencystand ingcommittee.org/iasc-reference-group-mental-health-an d-psychosocial-support-emergency-settings/iasc-guidanc e-basic-psychosocial-skills-guide-covid-19-responders [Accessed 10 September 2021]

[54] Taylor S. The psychology of pandemics: Preparing for the next global outbreak of infectious disease. Cambridge Scholars Publishing; 2019.

[55] Lep Ž, Babnik K, Hacin Beyazoglu K. Emotional Responses and Self-Protective Behavior Within Days of the COVID-19 Outbreak: The Promoting Role of Infor- mation Credibility. Front. Psychol. 2020;11:1846. DOI: 10.3389/fpsyg.2020.01846

[56] Jones V, Yates J, Reid A. Letter in response to article "COVID-19: the first 100 days in the south of Ireland. Ir Med J. 2021;114:P287.

[57] Kinman G, Grant C. Presenteeism during the COVID19 pandemic: risks and solutions. Occup Med. 2021;71(6/7):243-4. DOI: 10.1093/occmed/kqaa193

[58] Tempany M, Leonard A, Prior AR, et al. The potential impact of post-COVID symptoms in the healthcare sector. Occup Med. 2021;71(6-7):284-9. DOI: 10.1093/occmed/kqab109

[59] Kinman G. Sickness presenteeism at work: prevalence, costs and management. Br Med Bull. 2019;129(1):69-78. DOI: $10.1093 / \mathrm{bmb} / \mathrm{ldy} 043$

[60] Gaber TA-ZK, Ashish A, Unsworth A. Persistent postcovid symptoms in healthcare workers. Occup Med. 2021;71(3):144-6. DOI: 10.1093/occmed/kqab043

[61] Goto E, Ishikawa H, Okuhara $\mathrm{T}$, et al. Presenteeism among workers: health-related factors, work-related factors and health literacy. Occup Med. 2020;70(8):564-9. DOI: $10.1093 /$ occmed/kqaa168

[62] Taylor AK, Kingstone T, Briggs TA, O’Donnell CA, Atherton H, Blane DN, Chew-Graham CA. Reluctant pioneer: A qualitative study of doctors' experiences as patients with long COVID. Health Expect. 2021;24(3):833-42. doi: 10.1111/hex.13223. Epub 2021 Mar 22. Erratum in: Health Expect. 2021;24(5):1902.

[63] Vos J. The Psychology of COVID-19: Building Resilience for Future Pandemics. SAGE Publications. 2021:1-92.

[64] Abdelhafiz AS, Alorabi M. Social Stigma: The Hidden Threat of COVID-19. Public Health Front. 2020;8:429. DOI: 10.3389/fpubh.2020.00429

[65] Bhanot D, Singh T, Verma SK, Sharad S. Stigma and Discrimination During COVID-19 Pandemic. Public Health Front. 2021;8:577018. DOI: 10.3389/fpubh.2020. 577018

[66] Duan W, Bu H, Chen Z. COVID-19-related stigma profiles and risk factors among people who are at high risk of contagion. Soc Sci Med. 2020;266. DOI: 10.1016/j.socscimed.2020.113425

[67] Ransing R, Ramalho R, de Filippis R, et al. Infectious disease outbreak related stigma and discrimination during the COVID-19 pandemic: Drivers, facilitators, manifestations, and outcomes across the world. Brain Behav. Immun. 2020;89:555-8. DOI: 10.1016/j.bbi.2020. 07.033

[68] Grover S, Singh P, Sahoo S, Mehra A. Stigma related to COVID-19 infection: Are the Health Care Workers stigmatizing their own colleagues? Asian J Psychiatr. 2020;53:102381. DOI: 10.1016/j.ajp.2020.102381

[69] Mostafa A, Sabry W, Mostafa NS. COVID-19-related stigmatization among a sample of Egyptian healthcare workers. PLoS One. 2020;15(12):1-15. DOI: 10. 1371/journal.pone.0244172

[70] Ramaci T, Barattucci M, Ledda C, Rapisarda V. Social stigma during COVID-19 and its impact on HCWs outcomes. Sustainability. 2020;12(9):3834.

[71] Thayer JF, Verkuil B, Brosschotj JF, Kevin K, West A, Sterling C, Christie IC, Abernethy DR, Sollers 
JJ, Cizza G, Marques AH. Effects of the physical work environment on physiological measures of stress. Eur J Prev Cardiol. 2010;17(4):431-9. DOI: 10.1097/HJR.0b013e328336923a

[72] Sundstrup E, Hansen ÅM, Mortensen EL, Poulsen OM, Clausen T, Rugulies R, Møller A, Andersen LL. Retrospectively assessed physical work environment during working life and risk of sickness absence and labour market exit among older workers. Occup Environ Med. 2018;75(2):114-23. DOI: 10.1136/oemed-2016-104279

[73] Lund T, Labriola M, Christensen KB, Bültmann U, Villadsen E. Physical work environment risk factors for long term sickness absence: Prospective findings among a cohort of 5357 employees in Denmark. BMJ-BRIT MED J. 2006;332(7539):449-52. DOI: 10.1136/bmj.38731.622975.3A

[74] McCoy JM, Evans GW. Physical work environment. In: Barling J, Kelloway EK, Frone M (eds.). Handbook of work stress. Thousand Oaks, CA: Sage Publications. 2005;219-45.

[75] Nyashanu M, Pfende F, Ekpenyong M. Exploring the challenges faced by frontline workers in health and social care amid the COVID-19 pandemic: Experiences of frontline workers in the English Midlands region, UK. J Interprof Care. 2020;34(5):655-61. DOI: $10.1080 / 13561820.2020 .1792425$

[76] Nguyen LH, Drew DA, Graham MS, Joshi AD, Guo CG, Ma W, Mehta RS, Warner ET, Sikavi DR, Lo CH, Kwon S. Risk of COVID-19 among front-line health-care workers and the general community: a prospective cohort study. Lancet Public Health. 2020;5(9):e475-e483. DOI: 10.1016/S2468-2667(20)30164-X

[77] Taylor RR, Kielhofner GW. Work-related impairment and employment-focused rehabilitation options for individuals with chronic fatigue syndrome: A review. J Ment Health. 2005;14(3):253-67. DOI: 10.1080/09638230500136571

[78] Lee J, Kim H-R, Lee D-W, Kang M-Y. Interaction between occupational physical burdens and low job control on musculoskeletal pain: Analysis of the 5th Korean Working Environment Survey. J. Occup. Health. 2021;63(1):e12244. DOI: 10.1002/1348-9585.12244

[79] McKinney J, Connelly KA, Dorian P, Fournier A, Goodman JM, Grubic N, Isserow S, Moulson N, Philippon F, Pipe A, Poirier P. COVID-19-myocarditis and return to play: Reflections and recommendations from a canadian working group. Can J Cardiol. 2021;37(8):1165-74. DOI: 10.1016/j.cjca.2020.11.007

[80] Durand M-J, Vézina N, Richard M-C. Concept of margin of manoeuvre in return to work. In: Schultz IZ, Gatchel RJ (Eds.). Handbook of return to work: from research to practice. Boston: Springer; 2016. pp. 53-65.

[81] Durand MJ, Vézina N, Baril R, Loisel P, Richard MC, Ngomo S. Margin of manoeuvre indicators in the workplace during the rehabilitation process: a qualitative analysis. J. Occup. Rehabil. 2009;19(2):194-202. DOI: 10.1007/s10926-009-9173-4

[82] European Agency for Safety and Health at Work. COVID-19 infection and long covid - guide for managers. 2021. Available from: https://osha.europa.eu/en/ publications/covid-19-infection-and-long-covid-guide-m anagers/view [Accessed 20 October 2021]
[83] Chu L, Fuentes LR, Marshall OM, Mirin AA. Environmental accommodations for university students affected by myalgic encephalomyelitis/chronic fatigue syndrome (ME/CFS). Work. 2020;1-12. DOI: 10.3233/wor-203176

[84] Schreuder KJ, Roelen CAM, Koopmans PC, Groothoff JW. Job demands and health complaints in white and blue collar workers. Work. 2008;31(4):425-32.

[85] Roelen C, van Rhenen W, Schaufeli W, van der Klink J, Magerøy N, Moen B, Bjorvatn B, Pallesen S. Mental and physical health-related functioning mediates between psychological job demands and sickness absence among nurses. J Adv Nurs. 2014;70(8):1780-92. DOI: 10.1111/jan.12335

[86] NHS Plus Evidence based guideline project. Workplace management of chronic fatigue syndrome. [Internet]. Available from: https://www.nhshealthatwork.co.uk/imag es/library/files/Clinical\%20excellence/CFS_full_guidelin e.pdf [Accessed 15 August 2021]

[87] Löfgren M, Schult ML, Öhman A, Julin P, Ekholm J. Fibromyalgia syndrome or chronic fatigue syndrome/myalgic encephalomyelitis and factors influencing work disability in women. In Schultz IZ, Gatchel R (Eds.), Handbook of return to work. Springer, Boston, MA. 2016: pp. 459-480.

[88] Eisenberger R, Huntington R, Hutchison S, Sowa D. Perceived organizational support. J Appl Psychol. 1986; 71(3):500-7. DOI: 10.1037/0021-9010.71.3.500

[89] Roemer A, Harris C. Perceived organisational support and well-being: The role of psychological capital as a mediator. SA J. Ind. Psychol. 2018;44(1):1-11.

[90] Shanock LR, Eisenberger R, Heggestad ED, Malone G, Clark L, Dunn AM, Kirkland J, Woznyj H. Treating employees well: The value of organizational support theory in human resource management. Psychol-Manag J. 2019;22(3-4):168-91. DOI: 10.1037/mgr0000088

[91] Viitala R, Tanskanen J, Säntti R. The connection between organizational climate and well-being at work. Int. J. Organ. Anal. 2015;23(4):606-20. DOI: 10.1108/IJOA-102013-0716

[92] Schmidt B, Herr RM, Jarczok MN, Baumert J, Lukaschek K, Emeny RT, Ladwig KH. Lack of supportive leadership behavior predicts suboptimal self-rated health independent of job strain after 10 years of follow-up: findings from the population-based MONICA/KORA study. Int Arch Occup Environ Health. 2018;91(5):623-31. DOI: 10.1007/s00420-018-1312-9

[93] George TJ, Atwater LE, Maneethai D, Madera JM. Supporting the productivity and wellbeing of remote workers: Lessons from COVID-19. Organ. Dyn. 2021:100869. DOI: 10.1016/j.orgdyn.2021.100869

[94] Labrague LJ, De los Santos JA. COVID-19 anxiety among front-line nurses: Predictive role of organisational support, personal resilience and social support. J. Nurs. Manag. 2020;28(7):1653-61. DOI: 10.1111/jonm.13121

[95] Lee H. Changes in workplace practices during the COVID19 pandemic: the roles of emotion, psychological safety and organisation support. JOEPP. 2021;8(1):97-128. DOI: 10.1108/JOEPP-06-2020-0104

[96] Meyer B, Zill A, Dilba D, Gerlach R, Schumann S. Employee psychological well-being during the COVID-19 pandemic in Germany: A longitudinal study of demands, 
resources, and exhaustion. Int. J. Psychol. 2021;56(4):53250. DOI: 10.1002/ijop. 12743

[97] Cohen S, Underwood LG, Gottlieb BH. Theoretical and historical perspective. In Cohen S, Underwood LG, Gottlieb, BH (Eds.). Social support measurement and intervention: A guide for health and social scientists. Oxford University Press; 2000: pp. 3-25.

[98] Goldsmith DJ. Communicating social support. Cambridge University Press: 2004.

[99] van Servellen G. Communication skills for the health care professional: Concepts, practice, and evidence. Jones and Bartlett Publishers; 2nd ed; 2009.

[100] Lakey B, Cohen S. Social support theory and measurement. In Cohen S, Underwood LG, Gottlieb, BH (Eds.), Social support measurement and intervention: A guide for health and social scientists. Oxford University Press; 2000: pp. 29-52.

[101] Wills TA, Shinar O. Measuring perceived and received social support. In Cohen S, Underwood LG, Gottlieb, BH (Eds.), Social support measurement and intervention: A guide for health and social scientists. Oxford University Press; 2000: pp. 86-135.

[102] Salvagioni DA, Melanda FN, Mesas AE, González AD, Gabani FL, Andrade SM. Physical, psychological and occupational consequences of job burnout: A systematic review of prospective studies. PLoS One. 2017;12(10):e0185781. DOI: 10.1371/journal.pone. 0185781

[103] Lou NM, Montreuil T, Feldman LS, Fried GM, LavoieTremblay M, Bhanji F, Kennedy H, Kaneva P, Drouin S, Harley JM. Evaluations of Healthcare Providers' Perceived Support From Personal, Hospital, and System Resources: Implications for Well-Being and Management in Healthcare in Montreal, Quebec, During COVID-19. Eval Health Prof. 2021;27:01632787211012742. DOI: $10.1177 / 01632787211012742$

[104] Schultz IZ, Chlebak CM, Stewart AM. Impairment, disability, and return to work. In Schultz IZ, Gatchel RJ (Eds.). Handbook of return to work: from research to practice. Springer, Boston, MA; 2016: pp. 1-25.
[105] Wrzesniewski A, LoBuglio N, Dutton JE, Berg JM. Job crafting and cultivating positive meaning and identity in work. In Bakker AB (Ed.), Advances in positive organizational psychology. Emerald Group Publishing; 2013: pp. 281-302.

[106] Bakker AB, Costa PL. Chronic job burnout and daily functioning: A theoretical analysis. Burn Res. 2014;1(3):112-9. DOI: 10.1016/j.burn.2014.04.003

[107] Joie-La Marle C, Parmentier F, Vinchon F, Storme M, Borteyrou X, Lubart T. Evolution and impact of self-efficacy during French COVID-19 confinement: A longitudinal study. J Gen Psychol. 2021;148(3):360-81. DOI: $10.1080 / 00221309.2021 .1904815$

[108] Sylvia LG, George N, Rabideau DJ, Streck JM, Albury E, Hall DL, Luberto CM, Mizrach HR, Perez GK, Crute S, Mehta DH. Moderators of a resiliency group intervention for frontline clinicians during the COVID19 pandemic. J Affect Disord. 2021;293:373-8. DOI: 10.1016/j.jad.2021.06.036

[109] Roberts NJ, McAloney-Kocaman K, Lippiett K, Ray E, Welch L, Kelly C. Levels of resilience, anxiety and depression in nurses working in respiratory clinical areas during the COVID pandemic. Respir. Med. 2021;176:106219. DOI: 10.1016/j.rmed.2020.106219

[110] NHS Employers. Supporting recovery after long COVID. 2021. Available from: https://www.nhsemployers.org/art icles/supporting-recovery-after-long-covid [Accessed 15 November 2021]

[111] Van Herck M, Goërtz YM, Houben-Wilke S, Machado FV, Meys R, Delbressine JM, Vaes AW, Burtin C, Posthuma R, Franssen FM, Hajian B. Severe Fatigue in Long COVID: Web-Based Quantitative Follow-up Study in Members of Online Long COVID Support Groups. J Med Internet Res. 2021;23(9):e30274. DOI: $10.2196 / 30274$ 